\title{
Reform and Practice of College Physics Course Teaching Pattern in Agricultural Universities Based on Engineering Education Professional Certification
}

\author{
Bing ZHOU, Wen-dou WU, Ji-yan $\mathrm{HE}^{*}$ and Ya-ping PENG
}

Yunnan Agricultural University, Kunming, Yunnan, China

${ }^{*}$ Corresponding author

\begin{abstract}
Keywords: Engineering Education; Professional Certification; Mixed Teaching; Agricultural Colleges and Universities; College Physics.
\end{abstract}

\begin{abstract}
Since the professional certification has been introduced in the engineering education of universities, the physics curriculum education of agricultural colleges and universities have gradually begun to profound consider it. Changing the single teaching mode of the traditional classroom and introducing the mixed teaching have become an important thing in university physics teaching reform, and it is also a significant practice to explore the new teaching pattern. Taking the college physics course of Yunnan Agricultural University as an example, this paper discusses the ways and results of the practice of College Physics Teaching mode reform under the background of engineering education professional certification, which can be used to reference for similar colleges.
\end{abstract}

\section{Introduction}

The reform of higher education in China has never stopped. Especially for the engineering majors of colleges and universities, the reforms include "Undergraduate Teaching Level Assessment" of the Ministry of Education, "Audit Evaluation", "Quality Engineering", "Engineering Postgraduate Students", "excellent engineer plan" and "engineering certification". After decades of development, higher education in China has achieved considerable development [1].

The development of engineering education in colleges and universities is an essential support for promoting China's implementation of the "Made in China 2025" and "Internet Plus" strategies. China's engineering education, accepted by international education organization, will be able to promote domestic students to participate international communication. The Washington Accord, established in 1989, is currently the most influential international mutual recognition agreement for engineering education. China joined the Washington Accord in 2013 as a preparatory member and became an official member in 2016. This certification idea is well know, carrying out the professional certification of engineering education has become one of the leading directions for the engineering majors in universities of China [2].

College physics courses are an important public cause for non-physics students in science and engineering universities. In the process of imparting knowledge, the course can cultivate students' abilities of learning, analyzing and solving problems, which can enhance students' natural science literacy. The coordinated development of knowledge, ability and quality for students is a fundamental element in the engineering education system [3].

Engineering education professional certification requires that the basic concepts of natural science were applied to the appropriate representation of complex engineering problems, in teaching university physics. At the same time, it makes the students familiar with the basic ideas and methods of physics and trains the students' ability to apply physics concepts and patterns to solve practical engineering technical problems. In recent years, many agricultural colleges have more or less compressed the hours of college physics courses. Under the pressure of less hours for more contents, how to stimulate students' interest in learning, how to effectively improve students' ability to analyze and solve problems, and how to cultivate their innovative consciousness and the spirit of innovation are problems that many physics educators have concerned and discussed in recent years [4]. In order to solve these problems, we have introduced some specific cases in the 
classroom teaching, combined with the traditional and inquiry-based teaching mode. With imparting physical knowledge, we strengthened the application of the thought and method of physics pattern in practice. Students are divided into experimental classes and compared classes for teaching practice. It is found that the combination of the traditional pattern and the inquiry-based teaching pattern in the teaching of college physics courses has promoted effect on the achievement of the target of the engineering professional education certification.

\section{Teaching Pattern}

Since the engineering education professional certification has been implemented in 2016, the physics course of Yunnan Agricultural University has actively explored and tried to teach in mixed mode. The teaching practice has been carried out by adopting the mode of combination of receptive teaching and exploratory teaching, and achieved remarkable results. It is shown that the mixed mode of teaching is beneficial to mobilize students' enthusiasm and initiative, especially for innovative consciousness. The following are some specific practical processes in the teaching practice.

\subsection{Traditional Teaching Pattern}

The style of traditional teaching pattern is the receptive teaching. This traditional unitary teacher-centered pattern evaluates student's ability of accept knowledge and the investment situation of learning activities in class through practicing and asking questions in class. For example, fluid mechanics is an important part of university physics courses in agricultural colleges, wherein the Bernoulli's equation is the kinetic equtation about ideal fluid of steady flow. In the process of the traditional teaching, teacher deduces Bernoulli's equation through the function theorem and continuity principle [5]. The equation shows that: when the ideal fluid is steady flowing, the sum of kinetic energy, potential energy and pressure per unit volume of fluid at that point is equal to a constant. In class, teacher guides students to learn the application of Bernoulli equation in water conservancy, chemical engineering, shipbuilding, aviation and other departments, and enumerate patterns of small hole current velocity, multiple tubes, and nebulizers and so on. Then teacher gives the students corresponding hints to guide them to find out more applications about Bernoulli's equation after class, and to strengthen the cognition of knowledge.

On the liquid surface, the surface of the liquid tend to shrink due to presence of surface tension. Therefore, there are special properties different from those inside the liquid [5]. Due to the effect of surface tension, liquid has the the phenomenon such as additional pressure, capillary phenomenon, and hydrophilic or hydrophobic and other phenomena,which are widely used in agriculture. While analyzing these phenomena step by step, teacher guides the students through the combination of life phenomenon and formula, and further induce students to think and axplore deeply.

In the theory of gas dynamics, the transition process from non-equilibrium state to equilibrium state of the system is called gas transport process [5]. Because agricultural students have weak foundation of mathematics, when teaching the three transportation rules, teachers weaken the theoretical derivation of the three transportation phenomena and emphasize the causes and results of the three processes, but guide students to find the intrinsic connections between the three phenomena that seems to be unrelated to each other.

\subsection{Exploratory Teaching Pattern}

The exploratory teaching pattern is student-centered and case-oriented, teaching can be completed either in class or after class. We use the Bernoulli equation teaching mode mentioned before as an example, under the guidance of teachers, students will find that many natural phenomena are related to Bernoulli's equation after class. For example, international routes do not allow two ships to go forward side by side. Through analysis, students can see that: when the two vessels are traveling side by side with a small distance, the speed of the water flow between the two vessels will be greater than the outside. According to the Bernoulli equation, the pressure at the 
outside of the two ships is greater than the between, so that the water will squeeze the two ships into the middle, causing the two ships to collide. This part of the teaching cases also like this: the spinning ball in ball games has great power. The different flight path of the spinning ball is caused by the different air flow around the ball. When the normal ball moves horizontally, the flow lines above and below the ball are symmetrical and the velocity are same, and no pressure difference is generated. Now consider the spin, when the ball rotates counterclockwise, the air around it also rotates, causing the air under the ball to flow at a high velocity and a low pressure, while the above moves at a low velocity and a high pressure. The rotating ball is thus under a downward force, and the trajectory bends downwards. With the guidance of inquiry interest, students can find more and more examples,such as aircraft takeoff,the self-suction hot water shower, the carburetor of a gasoline engine, etc.

In addition, when learning surface tension content, students feel that they need to use a lot of mathematics and mechanics knowledge, which is more obscure and difficult to learn. But under the guidance of teacher and use the exploratory teaching mode to carry out teaching precess, students will find that this knowledge point is closely related to life and production, and thus develop a strong interest in learning. The simplest example of teaching is the use of surface tension principles to help clean the mouth. Since the surface tension of water is greater than the the toothpaste fluid, rinse mouth first with clean water and then brush with toothpaste. At this time, the toothpaste fluid can fill the entire mouth under the surface tension of water, removing bad breath and dirt more thoroughly.

When using exploratory teaching pattern to teach three kinds of transport laws, start from the simplest household thermos bottle insulation principle, find that the simple design of the thermos bottle which prevent heat convection, heat conduction and heat radiation so that it can play a role in insulation, and thereby recognize the transport law of the gas.

By using exploratory teaching pattern, students can also find that physics is closely related to modern science and technology, thus arousing strong interest in learning. For example, gas diffusion electrode is a three-phase (solid, liquid and gas) membrane electrode [6]. It can measure the content of the gas and is often used to monitor some trace components in gas, widely used to monitor certain traces of harmful gases in the environment, factories, and mine air. The thermal conductivity gas sensor is an electrical class gas sensor [7], it's a device that perceives certain gases and concentrations in the environment, which can convert information related to gas type and concentration into an electric signal so that the design of detection, monitoring, data analysis and alarm can be conveniently completed.

\section{Comparison of Pattern Results}

The mixed teaching pattern of the university physics course at Yunnan Agricultural University was formally implemented in the experimental class in 2016.

The following is a comparative analysis of students' academic performance and teaching acceptance score of experimental class and control class before and after the implementation of mixed learning pattern, and objectively evaluate the impact of mixed teaching reform on the effect of curriculum teaching and students' acceptance of the pattern.

Table 1. Comparison of Teaching Evaluation Results among Students

\begin{tabular}{llcc}
\hline Opening time & $\begin{array}{l}\text { Student } \\
\text { attendance }\end{array}$ & $\begin{array}{l}\text { Average score of } \\
\text { student assessment }\end{array}$ & The total average \\
\hline 2016-2017 First semester & 300 & 80.88 & 81.26 (control group) \\
2016-2017 Second semester & 300 & 81.63 & 95.74 (test group) \\
2016-2017 First semester & 300 & 94.83 & 96.65 \\
2016-2017 Second semester & 300 & & \\
\hline
\end{tabular}




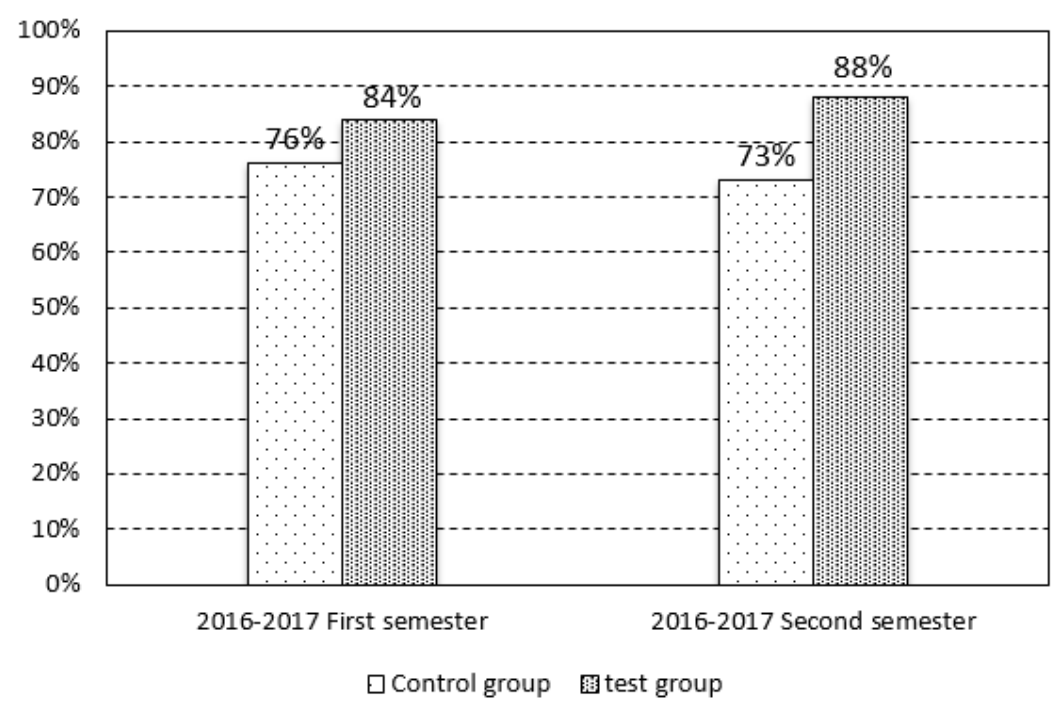

Figure 1. Comparison of Pass Rate between Control Group and Test Group

It can be seen from Figure 1, after implementing the mixed teaching mode, the score of student evaluation of teaching points lift from 81.26 points to 95.74 points, which increased $17.8 \%$, and it can be seen that students accept mixed teaching mode.

\section{Conclusion}

Based on the curricular characteristics and the actual teaching situation, the "College Physics" in Yunnan Agricultural University has built a mixed teaching pattern during 2016-2017, which is that teacher talks in class, students explore and discuss after class, and students discuss and communicate together. This pattern has aroused the students' enthusiasm as well as positivity for learning, and has achieved remarkable results in teaching. And have contributed to the enhancement of professional students' natural science literacy and improvement of solving practical engineering problems. In the process of design and implementation of mixed mode teaching, curriculum teachers and students can fully interact with each other and improve together.

(1) Compare the results before and after implementation of the mixed learning pattern in two semesters, the average pass rate of students has increased by $11.5 \%$ after implementation of the mixed learning pattern. It can be seen that mixed learning can improve teaching quality and have an ideal teaching effect.

(2) After the implementation of the mixed learning pattern, the student's assessment of the curriculum has increased from 81.26 to 95.74 , an increase of $17.8 \%$. It can be seen that students are very receptive to mixed learning.

From the above data, the teaching effect of this teaching pattern reform and students' acceptance of mixed-mode teaching can be tested. Students accepted and welcomed the mixed teaching pattern, and the quality of the course was significantly improved.

To sum up, combined with the current requirements for professional engineering certification in universities, the hybrid teaching practice of the "University Physics" course of Yunnan Agricultural University is effective, which provides reference cases for the reform of university physics teaching in other similar institutions. This teaching method has good effect on improving students' enthusiasm for independent study of university physics and enhancing students' natural science quality.

\section{References}

[1] Yonghui Zhao, Shuyu Liu, Discussion on Teaching Reform under the background of Engineering Certification in universities and Colleges [J]. The Science Education Article Collects, 2017 (09): 32-34+51. 
[2] Hailei Cao, Exploration on the teaching reform of engineering law in the environment of engineering education certification [J]. Guangdong Chemical Industry, 2017, 44(19): 188-189+204.

[3] Yongmei Zhang, Xufeng Zhang, Xinglai Liu, et al, Thinking and practice of College Physics Teaching Pattern in engineering education professional certification [J]. Physics and Engineering, 2017, 27 (Z1): 134-137.

[4] Anhui Liu, Yaofu Heng, Discussion on the Teaching of Different Levels of College Physics in Application-oriented Universities [J]. Journal of Tianzhong, 2012, 27 (2): 101-102.

[5] Yaling Yang, Kaiming Wang, Bing Zhou, College Physics [M]. Beijing: China Agriculture Press, 2014.

[6] Cuiju Feng, Hailing Li, Analysis of the Teaching Science of University Physics Case Study [J]. Journal of North China Institute of Science and Technology, 2012, 9 (4): 99-101.

[7] Xiaochun Chen, Bing Zhou, College physics experiment course [M]. Beijing: China Agriculture Press, 2010: 154-155. 